\title{
Family Integrity Among Older Caregivers of Relatives With Dementia ${ }^{1}$
}

\author{
Sara Guerra \\ Universidade de Aveiro, \\ Aveiro, Portugal
}

\author{
Daniela Figueiredo \\ Universidade de Aveiro, \\ Aveiro, Portugal
}

\author{
Marta Patrão \\ Universidade de Aveiro, \\ Aveiro, Portugal
}

\author{
Liliana Sousa ${ }^{2}$ \\ Universidade de Aveiro, \\ Aveiro, Portugal
}

\begin{abstract}
The construct of family integrity denotes that older persons' attainment of ego integrity is linked to family relationships. Family integrity is the positive outcome (overall satisfaction with life); disconnection (dissatisfaction) and alienation (estrangement) are the negative outcomes. This study focuses on elderly people who are primary caregivers of relatives with dementia, and examines their experience of events related to that role, which are perceived as being of influence on their sense of family integrity. The sample included 26 participants. Open-ended interviews were conducted. The interview transcripts were submitted to content analysis. The main findings suggest that caregivers who experience family integrity tend to embrace the new life demand associated with the caregiving role, while those tending towards disconnection struggle to maintain their pre-existing goals, and those experiencing alienation tend to feel helpless. Caring for a relative with dementia has an impact on multiple aspects of family life.
\end{abstract}

Keywords: adult development, dementia, caregivers, family relations

\section{Integridade Familiar em Pessoas Idosas Cuidadores de Familiares com Demência}

\begin{abstract}
Resumo: O construto integridade familiar significa que o processo de construção da integridade do ego em pessoas idosas está associado às relações familiares. A integridade familiar (satisfação com a vida e relações familiares) é o resultado positivo; desconexão (insatisfação) e alienação (afastamento) constituem resultados negativos. O objetivo deste estudo foi investigar pessoas idosas, cuidadores primários de familiares com demência, examinando a sua experiência de eventos relacionados com esse papel, percebidos como influenciando o seu sentido de integridade familiar. A amostra compreendeu 26 participantes idosos, cuidadores de familiares com demência. Foram realizadas entrevistas abertas com roteiro semiestruturado. As transcrições das entrevistas foram submetidas a análise de conteúdo. Os principais resultados sugerem que os cuidadores no caminho da integridade familiar reveem os seus projetos de vida anteriores, enquanto aqueles em desconexão lutam para manter os projetos anteriores e aqueles na via de alienação tendem a abandonar os projetos. Cuidar de um familiar com demência apresenta múltiplos impactos na vida familiar.
\end{abstract}

Palavras-chave: desenvolvimento do adulto, demência, cuidadores, relações familiares

\section{Integridad Familiar en Cuidadores Ancianos de Familiares con Demencia}

\begin{abstract}
Resumen: El constructo de la integridad familiar indica que la construcción de la integridad del yo en ancianos está vinculada a las relaciones familiares. La integridad familiar (satisfacción con la vida y las relaciones familiares) es positivo; desconexión (insatisfacción) y la alienación (sensación de lejanía) son negativos. Este estudio centra ancianos cuidadores primarios de familiares con demencia, y examina su experiencia de acontecimientos relacionados con esa función, percibido como influido la construcción de integridad familiar. La muestra consta de 26 participantes. Entrevistas abiertas con rutero semiestructurado se realizaron. Las transcripciones fueran sometidas a análisis de contenido. Los principales resultados indican que los cuidadores en integridad hacen la revisión de proyectos de vida; aquellos en desconexión luchan para mantener los proyectos anteriores; y aquellos en alienación tienden a abandonar los proyectos de vida. El cuidado de un familiar con demencia es una tarea compleja, con múltiples impactos que necesitan más atención.
\end{abstract}

Palabras clave: desarrollo del adulto, demencia, cuidadores, relaciones familiares

Key themes in gerontological research have been related to older people's health status (e.g., functional dependency, cognitive decline or impairment), and the role

\footnotetext{
${ }^{1}$ Paper taken from the first author's doctoral dissertation under the fourth author' supervision and the second author' co-supervision, and the collaboration of the third author; the dissertation was defended in 2012, in the Doctoral Program of Gerontology and Geriatrics at the Universidade de Aveiro in collaboration with the Universidade do Porto.

Support: Fundação para a Ciência e Tecnologia (Scholarship - SFRH/ $\mathrm{BD} / 38109 / 2007)$.

${ }^{2}$ Correspondence address:

Liliana Sousa. Departamento de Educação, Universidade de Aveiro, Campus Universitário de Santiago, 3810-193. Aveiro, Portugal. E-mail: lilianax@ua.pt
}

that families play, particularly in terms of family caregiving of dependent elderly family members (Sousa, 2009). The construct of family integrity (King \& Wynne, 2004) offers a framework when examining the lives of older people and their family relationships, from a developmental perspective. This approach posits that the process involved in attaining ego integrity is inextricably bound up with the broader processes of constructing meaning and relational development at the family level. As such, the process of developing a sense of ego integrity is an individual, subjective experience that takes place within the context of family relationships, which, in turn, affects perceptions of family integrity. Considerable variation exists in the extend to which older people are able to achieve a sense of family integrity (King \& Wynne, 2004; 
Marques \& Sousa, 2012; Nadeau, 2001). Family integrity refers to a positive outcome of this process, characterized by an overall sense of peace and satisfaction with life and family relations experienced by the older person; in contrast, family disconnection (overall dissatisfaction with life) and alienation (sense of estrangement) constitute negative outcomes. However, family integrity needs to be understood within the context of the growing diversity of family structure and relationships. As such, family should be defined as the group of persons linked by feelings of trust, mutual support, and a common destiny (World Health Organization [WHO], 1994).

The literature on family caregiving shows that older people are often caregivers of other dependent older people (Barbosa, Figueiredo, Sousa, \& Demain, 2011). In this study, the authors focus on older caregivers of relatives with dementia, which is an increasingly common situation (Barbosa et al., 2011). Until recently, studies that addressed the process of providing care for older persons mostly focused on possible negative consequences of this care. Although recent studies also address positive outcomes, these studies do not include the process of building integrity, which has been identified as a crucial life task in old age (Erikson, 1950; King \& Wynne, 2004; Lane, Podgorski, Noronha, \& King, 2012). It has been widely recognized that caring for a family member with dementia is one of the most stressful caregiving experiences, due to the patient's cognitive and behavioral difficulties. Therefore, it is particularly relevant to understand how older caregivers of relatives with dementia deal with the process of building their sense of family integrity versus disconnection and alienation.

\section{The Task of Building Family Integrity When Caring for a Relative With Dementia}

Caring for a person with dementia is considerably different from caring for a dependent person whose cognition is intact and who can co-operate (Boss, 2011; Pinto \& Barham, 2014). Family caregivers who reside with relatives with dementia are required to provide around the clock supervision; they also need to adapt to the care recipient's personality changes and communicational difficulties. Performing this task requires special knowledge, skills and strong motivation. Caregivers of people with dementia face, on average, three to fifteen years of exposure to stressful physical and psychosocial demands, which may lead to psychosocial distress and risky health behaviors on their part (Vitaliano, Zhang, \& Scanlan, 2003). Despite these negative aspects, usually described in terms of burden, stress and poor physical and mental health, many caregivers choose to provide this care until the end of the care recipient's life. Recent studies (Ducharme et al., 2011; Lane et al., 2012) have highlighted positive outcomes or rewards derived from the caregiving experience, which include a sense of satisfaction, achievement and pride in the caregiving role; increased sense of mastery; sense of purpose and meaning in life; improvements in family relationships among those involved in the caregiving process (caregivers, care-receivers and significant others).
Thus, it seems that those who define the caregiving role as a positive experience (finding meaning, despite the stress and burden associated) are able to derive personal growth from this role (Ducharme et al., 2011).

The concept of psychological integrity involves reconciling "the good" and "the bad" aspects of each situation. Integrity is of central importance to human wellbeing and results from the emotional integration of contrasting (i.e., positive and negative) aspects of the self. Integrity also involves achieving harmonious interactions with others in social contexts, especially in a multigenerational family context (Williamson, 1991). Achieving a sense of family integrity is a developmental task for older people, influenced by factors within the family system (King \& Wynne, 2004). The construction of ego integrity (Erikson, 1950), has been associated with the more general process of relational development, in which older people strive to establish bonds within their multi-generational family context. Erikson (1950) proposed an epigenetic model of human development comprising stages that each requires the resolution of dialectical tensions between two opposing dispositions. Ego integrity, in contrast with despair, stems from coming to terms with the realities of older age, and using this period to conduct a life review to integrate and make sense of past events; this process often involves interaction with family members (Marques \& Sousa, 2012). King and Wynne (2004) suggest that an older adult's efforts to achieve ego integrity are inextricably bound to a larger process that involves meaning construction (Nadeau, 2001) and relational development at the family level. Family integrity is the positive outcome of older adults' developmental striving to find meaning in their lives, characterized by overall satisfaction with life and with family relationships; these relationships are characterized by union and continuity within the family context (King \& Wynne, 2004). However, this process may also take on a negative direction, putting the older person at risk of either: (a) family disconnection, characterized by the overall dissatisfaction with life, infrequent contact, and a lack of meaningful communication between family members, resulting in a prevailing sense of isolation; or (b) alienation, when the level of disconnection is greater and stems from a lack of common values and family identity, such that a sense of isolation may lead to feelings of estrangement. The older person's ability to achieve family integrity depends on three functions of the family system (King \& Wynne, 2004). The first involves the transformation of relationships, as a reflection of ever changing lifecycle needs, and depends on mutuality and filial maturity. Mutuality (Wynne, 1984) is the ability to maintain a long-term commitment to family relationships and to reconstruct these in the face of lifecycle transitions. It is attained when prior basic relational functions (attachment or caregiving, communication, and shared problem-solving) have permitted the development of a positive relational foundation. Filial maturity, which derives from intergenerational mutuality, is attained when adult offspring develop the capacity to offer caring support to their aging parents, and the aging parents, in a 
reciprocal manner, become more able and willing to accept input from their children (King \& Wynne, 2004). This transformation depends on the family's ability to renegotiate intergenerational power hierarchies and to develop adult-toadult relationships between the older parents and their mature children (Williamson, 1991). However, this transformation can be difficult when an older family member suffers from dementia. Caring for a relative with dementia has been found to increase the risk of conflictual family relationships (Figueiredo, 2009) as a result of disagreements among family members regarding severity of the disease, diverging opinions about the best way to care for the patient, lack of involvement in the caregiving role, and distancing in the relationship between the caregiver and other family members, as caregiving is a full-time occupation. Depending on how these difficulties are managed, caregiving can also lead to closer, stronger relationships among family members (Ducharme et al., 2011; Lane et al., 2012).

The second function of the family system is the resolution or acceptance of past losses, disappointments or conflicts. This resolution becomes urgent when people face death (either their own or that of significant others) and demands that family members address old grievances, past cut-offs or losses that have gone unmourned, so that current family problems or crises (illness, financial difficulties) can be handled. This requires communication and the willingness and strength to confront emotionally charged issues (King \& Wynne, 2004; Walsh, 2012). Crucial to the integration of family experiences is the ability to grieve and to eventually let go of those attachments that cannot be restored. This family function conveys the ability of the older and younger family members to confront and "work through" losses or relational conflicts, whether past or present. This resolution or acceptance of loss may not be possible to achieve with a family member who has dementia. Dementia entails the gradual loss of functioning, along with financial and psychosocial dilemmas for families, which make the process of acceptance more difficult (the "long goodbye" as stated by Walsh, 2012). Dementia has been described as an "ambiguous loss" (Boss, 2011), as the family loses the capacity to work out emotional issues with the person with dementia, despite the fact that he or she is physically present, confusing the caring and mourning processes.

The third function is the creation of meaning and legacy, which is a process that benefits both the older family members, by maintaining their sense of purpose in the family, and the younger generations, who inherit a family legacy that in time will provide a model for their own aging process (Sousa, Silva, Santos, \& Patrão, 2010). This is accomplished through family storytelling, the passing on of shared interests, of life themes, and of values, through involvement in shared family activities and rituals. The creation of legacy and meaning can probably also be developed through caregiving, which has been described as being motivated by family values, such as repaying past kindness, fulfilling a sense of duty and responsibility, expression of love, maintaining the dignity of the cared-for person, and a family tradition (King \& Wynne, 2004; Sousa, Silva, Marques, \& Santos, 2009).
Based in these considerations, the objective of this qualitative, exploratory study was to examine the perceptions of family integrity among older people who are primary caregivers of relatives with dementia. It examines their subjective experience of events related to their role of caregiver that are perceived as influencing their construction of family integrity (versus disconnection and alienation). The study is relevant at a theoretical as well as an intervention level, as it advances knowledge regarding the processes associated with the construction of family integrity by focusing on the specific experience of family dementia caregiving.

\section{Method}

\section{Participants}

The sample consisted of 26 primary caregivers of relatives with dementia (16 women, 10 men) (Table 1). Although the majority of participants had some years of schooling, seven participants were illiterate. All caregivers cohabited with the care recipients and the majority of the participants were spouses, who cared for their wife or husband, at home. All participants were retired and 13 caregivers had been providing care for more than five years.

Table 1

Caregivers of People With Dementia: Socio-Demographic Characterization $(N=26)$

\begin{tabular}{lc}
\hline Characteristic & $N$ \\
\hline Gender & 16 \\
Female & $74.11 \pm 7.4$ \\
Mean age in years & \\
Marital status & 24 \\
Married & 1 \\
Divorced & 1 \\
Widowed & \\
Education & 7 \\
No schooling & 18 \\
4 to 6 years of schooling & 1 \\
Higher education & \\
Kinship with the person with dementia & 20 \\
Spouse & 4 \\
Children & 1 \\
Siblings & 1 \\
Mother-in-law & \\
Length of time as a caregiver & \\
1 to 2 years & \\
3 to 5 years & \\
More than 5 years & \\
\hline
\end{tabular}




\section{Instrument}

Socio-demographic data were obtained during the interview (gender, age, marital status, household composition, educational level, kinship with the person with dementia, and length of time as a caregiver). An open-ended interview following a semi-structured script based on King and Wynne (2004) and Sousa et al. (2009) (Table 2) was used. In this study, one question was added at the end of each domain, focusing on the possible influence of the caregiving role on the topics that were addressed.

Table 2

Family Integrity: Interview Script

Domain Questions

1. Family integrity (general)

Do you feel satisfied or at peace with your overall life and family relationships? What aspects of your family life are most/least satisfying? How do you deal with those aspects (negatives and positives)? What are your goals for the future in terms of your family and personal life? Although you may or may not see family members as much as you would like, do you feel close or connected to members of your family? If possible, tell me about one or two of your closer relationships.

Do you have regrets about any of your family relationships? Do you have a sense of "unfinished business" with any of your family members? If so, have you tried to address this issue? How (if at all)? Are there any issues or problems that you wish to discuss with someone in the family? If so, what do you think could help you to accept or solve those issues?

What aspects of family tradition and material inheritances have you passed on to younger family members? What would you still like to share or pass on to others (material and/or symbolic)? Do you feel that you have a meaningful and respected place in your family? How will you be remembered by family members after you are gone? How would you like to be remembered? Are there still things you would like to do or say to influence your family's memories of you?

How have your relationships with family members changed as you've gotten older? Do you think that your relationship with family members will change? If so, how? 4. Transformation Are there family members whom you can of relationships
Is it hard for you to ask family members for help or support? Are there family members who count on you for help or support? Is it hard for others to ask you for help or support?

\footnotetext{
Note. At the end of each domain: "Is there any event associated with caregiving that you think has influenced (positively or negatively) any of these aspects? If so, how?"
}

\section{Procedure}

Data collection. An exploratory, qualitative methodology was adopted. The directors of ten community services for older people were contacted, and informed about the purpose of the study. All the directors agreed to collaborate and appointed a practitioner who would mediate the contact with potential participants; the ten practitioners (female social workers) were contacted and informed about the nature of their collaboration, the objectives of the study, and the inclusion criteria for recruiting potential participants ( $\geq 65$ years old; primary caregiver for a relative with dementia - by answering if the person takes primary responsibility for the person who she/he cares for, during a period of at least two years; living and caring in the community; and able to express opinions). The practitioners contacted people who were eligible to participate in the study to explain the objectives of the study, what would be expected of them, and ask them permission to give the researcher their phone number. For those who agreed, the researcher made initial contact by phone, reiterating information about the study and explaining the recruitment procedures. All participants who were contacted agreed to collaborate and, after they indicate their interest in participating, a date for the interview was scheduled. At their request the interviews took place at the caregivers' homes. Informed consent agreements were signed before initiating the interviews, which lasted between 22 and 150 minutes. Data collection was concluded when the authors agreed that a saturation point (when information provided during interviews has been heard before, during prior interviews) had been reached (Mason, 2010). This point was determined in the following manner: the first author, who conducted and transcribed the interviews, asked the other three authors to read the interviews transcripts independently, and indicate whether they agreed that no new concepts were appearing in the final interviews. It should be noted that the saturation point depends largely on sample characteristics. The sample in this study was relatively homogenous; with a more heterogeneous sample of participants, the saturation point would probably be reached after conducting a greater number of interviews.

Data analysis. The interviews were audio-recorded, transcribed and submitted to content analysis, with family integrity constituting the conceptual framework (King \& Wynne, 2004; Sousa et al., 2009). First, two independent coders classified each participant in terms of the trajectory of his or her family relationships (family integrity, disconnection or alienation), starting with an analysis of his or her response to the question, "Do you feel satisfied or at peace with your life and family relationships?" After this initial classification, each coder independently read the interviews to confirm or modify this decision. Next, the researchers met to compare and discuss their proposed classifications, until agreement was reached about how to classify the family relationship trajectory of each participant. It should be emphasized that a person classified as being on one of these trajectories may not present all the features of that route, as this is an ongoing, constructive process in which some issues may already have been solved and others may still be in 
process (Sousa et al., 2009). Then, the analysis was undertaken to understand the participants' subjective experiences of specific events related to the caregiving role that they perceived as influencing their sense of family integrity. To this purpose, a categorization system was developed that involved the definition of categories and sub-categories. This process of gradually creating, reviewing and refining the categorization system was performed by two independent coders. Initially, each coder read the interviews and drew up a list of sub/categories, and then they met to compare ideas until they were able to agree on names and definitions for an integrated list (Table 3). The classification of the participants' responses into these sub/ categories was carried out by the first author and reviewed by the second author until full agreement was reached.

Table 3

Categories: Events Reported as Influencing the Sense of Family Integrity of Older Caregivers

\begin{tabular}{ll}
\hline Categories & Definition \\
\hline
\end{tabular}

Integrity (general)

1. Frequency of contacts

1.1. Increase

1.2. Decrease

2. Difficulty in pursuing life projects

Transformation of family relationships

3. Decrease in caregivers' reciprocity

4. Emotional proximity

4.1. Increase

4.2. Decrease

5. Confrontation of loss and death

Resolution of past losses and conflicts

6. Solving family conflicts

6.1. Facilitate

6.2. Difficult

Creation of meaning and legacy

7. Family appreciation of caregiver's role

8. Dissatisfaction with grandparents' role
Caregiving affects the frequency of contacts or meetings between caregivers and their extended family.

The frequency of contacts with members of the extended family increases, mainly due to caregivers' need for help in delivering support to the care receiver (e.g., transportation to medical appointments) which is provided mostly by adult children, but also by siblings.

The frequency of contacts (visits) with the multi-generational family (mostly children) decreases because caregivers find it difficult to leave the care receivers by themselves and the extended family finds it difficult to deal with the dementia.

Caregivers feel that the demands of the caregiving role (full-time occupation) prevent them from achieving personal goals and plans for their later life (spending more time with grandchildren, visiting family members more often, visiting their country of origin or their birthplace, more time for leisure).

Caregiving has a double consequence for caregivers: they ask for/need more help from family members (particularly children), and they receive fewer requests for help from family members, who note their lack of availability. Caregivers feel they do not (cannot) maintain reciprocal relationships with family members.

Caregivers feel that caring influences their emotional proximity to the family.

Caregivers' emotional proximity to the family increases, because the caregiving task improves the family bond (belonging, sharing, understanding, and mutual help).

Caregivers describe a decrease in their emotional proximity to the family (weakened sense of belonging), mainly because they feel that their family is not there for them.

Providing care confronts the caregivers with the loss (it is no longer the same person) and the impending death of the care receiver (usually, a significant and close relationship); as a consequence the caregiver is confronted with his/her own death.

Influence of caregiving on conflict or resentment resolution within the family.

Caregivers feel that the challenges, demands, and meanings of the illness and caregiving tasks facilitate family conflict resolution and generate feelings of cohesion and support, diminishing possible resentments.

Caregivers consider that the illness and associated care needs make it more difficult to resolve family conflicts: the caregiver has fewer opportunities to visit the relatives with whom s/he has a conflict. Conflicts may even be exacerbated and resentments may arise, particularly when the caregiver feels misunderstood: s/he is spending money on care and the family does not understand (often associated with inheritance); the family does not understand the caregiver's lack of time.

The caregiver feels that the family appreciates his/her role and commitment to the relative with dementia. The caregiver feels proud and respected by the family.

The caregiver experiences feelings of dissatisfaction and self-devaluation because $\mathrm{s} / \mathrm{he}$ has no time to be with grandchildren and to pass on the symbolic legacy. 


\section{Ethical Considerations}

This particular kind of research does not require the approval of an ethics committee, in Portugal. Notwithstanding, the procedures used in this study adhered to the ethical guidelines of The Helsinki Declaration.

\section{Results}

The classification of trajectories showed that almost two-thirds of participants were on the path towards family integrity $(n=17)$; the other third was evenly divided between disconnection $(n=5)$ and alienation $(n=4)$. The main experiences that were perceived as being of influence on caregivers' construction of family integrity (versus disconnection and alienation) fell into three domains: general integrity (difficulty in achieving life projects; increase/ decrease in the frequency of family contacts); transformation of family relationships (decrease of caregiver's reciprocity); and resolution of conflicts (difficulty in resolving family conflicts). The domain creation of meaning and legacy was not amongst the most cited, but two categories emerged within that domain: (a) family appreciation of the caregiver's role, which seemed to imply that caring may be viewed as a legacy in and of itself; (b) dissatisfaction with the role of grandparents, revealing that the lack of contact with the younger generations was felt to restrict the possibilities of leaving a symbolic legacy (in order to guarantee symbolic continuity after death).

\section{Difficulty in Pursuing Life Projects}

Caregivers who experienced family integrity stated that caring for a relative with dementia compromised their ability to accomplish projects they had anticipated for this period of their lives. Yet, they felt that "it had to be", accepting that caring resulted in less time for other activities, and they changed their plans in order to adapt to the caregiving situation.

I would like to spend more time with my children, but that is impossible. So, I use the telephone to communicate with them; and we are very close, that's what matters. (...) My life project at this time is to take care of my wife! (António, 81, husband)

Caregivers who experienced family disconnection described the difficulty of achieving life projects due to factors such as: upheaval (feelings of grief, and injustice), resignation (dealing with demands "as they can" and not knowing where they find the strength to cope with such a challenging illness), giving up (no longer having life projects, a loss which they also attribute to their own older age), and projects focused on the past (e.g., solving family conflicts). Benilde (65, mother-in-law) stated, "I don't have goals; not any longer!"

Caregivers in situations characterized by family alienation related their inability to achieve their life projects to factors associated with their poor health status, which were amplified by the caregiving demands. Filipe (83, husband) commented, "I see myself dying to live; I don't have anybody to help me. My legs are always shaking and my wife is very nervous!"

\section{Frequency of Family Contacts}

Participants from the family integrity group described a "decrease in the frequency of family contacts," mainly because of geographical distance, which did not, however, interfere with emotional proximity. Caregivers would have liked to be with their relatives more often, but they understood that their children did not visit them as often as they may have wished, for reasons such as residing and working abroad. Emotional proximity (in particular, support and companionship) was maintained by telephone contact and the frequent use of family photo albums. Hugo (86, husband) mentioned, "We don't see our family every day! However, I can see them every day in photos! We must accept this type of situation and try to focus on the good moments!" These caregivers felt that they had someone in their family (children, grandchildren, or siblings) with whom they could share what they thought and felt in relation to caregiving. Carina (65, daughter) stated, "Whenever there is a problem we talk [with my siblings] and make decisions. What comes up is promptly resolved!" Despite a reduction in the frequency of contacts, caregivers stated that they received the support they needed from their family members, and were easily able to identify the relatives who provided help. Lúcia (84, wife) said, "Yes! I have my daughters, my niece . . . if I need help, they help me!"

Caregivers from the family disconnection group described an increase in the frequency of contacts with one or two relatives who recognized their greater need for instrumental support, and often came to visit and help. Nonetheless, they expressed dissatisfaction with family relationships, describing feelings of isolation and loneliness. Sometimes they expressed some ambiguity in their perceptions; whereas they acknowledged that having someone who helped out suggested emotional proximity, they emphasized that this help came from only one or two family members. In their view, all family members (especially siblings and children) should fulfill their obligation to offer care. Some caregivers tried to cope with the situation without family support, hiding their feelings and the hardship they experienced.

My family is a disgrace . . . ! The daughter who comes here is a pearl and my son-in-law, too; and my son is also good, but he is so far away from here ... but brothers and so on should really be ashamed! (João, 78, husband)

There were also examples, mainly related to financial issues, of family break-ups or of avoidance of contact between family members (usually siblings or in-laws).

I stopped to talk to some relatives, especially my sister-in-law. She hurt me a lot; she robbed me and seized some land of mine. I feel very sad and angry ... I have done everything for her and look what she did to me! (Filipe, 83, husband) 
Frequency of family contacts was rarely addressed by participants from the alienation group.

\section{Decrease in Caregiver's Reciprocity}

In the group on a trajectory towards achieving family integrity, caregivers understood that they could not support other relatives while caring for the person with dementia; they also recognized that their relatives had to deal with other demands (professional and personal). Nonetheless, they still wished to receive support without having to ask for it. Alexandra (66, wife) said, "I wish my family could provide some support without being asked for it; it is horrible to always be asking for help, when they know that I need help!"

Caregivers from the family disconnection group stated that they did not ask for support, despite their needs. The main reasons for this were related to family conflicts, especially with in-laws, as a result of which they felt inhibited and tended to withdraw. Manuel (78, husband) stated, "I feel that now I have to ask for help because sometimes it's hard to cope. However, I can't help them as before!"

Caregivers in the family alienation group described insufficient instrumental and financial support from their family members. They reported experiencing feelings of injustice and anger; they felt pessimistic and blamed their relatives, who they felt should have provided support, but failed to do so. Marta (75, wife) mentioned, "My life is full of sadness. My husband is sick and so am I . . I have no support from my family. I have no family, nothing!" In a similar vein, these caregivers felt that their family requested less support from them, because they would be unable to provide that additional support. They described that they experienced shame, which inhibited their ability to ask their family members for help. They used to be independent and able to help others, and now they felt embarrassed about revealing their difficulties and need for help to their family members.

\section{Solving Family Conflicts}

References to hindering the resolution of family conflicts were rare for respondents in the family integrity group, while such references were both more frequent and intense for those from the groups characterized by family disconnection and alienation. Caregivers on the disconnection trajectory often described unresolved family conflicts and resentments (especially with siblings and in-laws) related to inheritance or family business (highlighting financial aspects). Respondents described these conflicts as longstanding; they blamed the other party for their continuation and related their own inability to resolve these difficulties to the lack of time they experienced due to their caregiving duties. In a way, caring seemed to exacerbate these problems, as in these situations the caregiver needed to focus their attention on the person with dementia, which made him or her feel powerless with respect to other family problems.

I sometimes feel sad and wonder why the family stopped talking to me. This started when I had a problem with my brothers. But nobody takes any interest! I feel sad because someone should tell them things can't go on like this! (Rodrigo, 82, husband)

The occurrence of family conflicts was associated with a loss of self-value. Rodrigo (82, husband) mentioned, "I don't put much value on life. I've always been a very lively and cheerful person (...) since the problems arose in my family, everything changed!"

Caregivers in circumstances of family alienation felt the need to discuss problems with their family members, especially because they felt misunderstood (e.g., in situations where they had to spend a lot of money on the person with dementia, or experienced a lack of time to interact with other relatives). As a result, they felt that caring involvements promoted family conflicts related to financial issues and personal matters.

Now I have more conflicts with my husband, because he's jealous because I spend a lot of time with my brother [person with dementia]. My children are a little jealous, too. However, my brother has always helped me though life; now I must help him! (Sandra, 66 , sister)

\section{Discussion}

The main limitation of these findings stems from the small sample size. In future studies, a larger sample, particularly of those on route to alienation and disconnection, would allow more detailed comparisons among the three trajectories, examining the influence of caregiver variables such as gender, academic status, kinship with the care receiver, and years of caregiving. It would also be of interest to analyze the influence of care receiver variables such as age, gender, and the stage of the illness. To increase our understanding of the feelings experienced by these older people, instruments that measure subjective well-being could also be used. We believe that, together with open-ended questions, a quantitative measure could be adopted to permit data triangulation and improve our understanding of respondents' comments. Despite these limitations, the study helps us to better understand how elderly people, who are primary caregivers of relatives with dementia, are constructing their sense of family integrity.

Most participants in this study seemed to be on a trajectory towards family integrity. As such, we surmise that providing care for a relative with dementia does not necessarily hinder the achievement of this positive outcome. However, for those elderly caregivers on a trajectory towards disconnection, we perceived that they were struggling with this role, and for those experiencing alienation, it seems likely that they did not have strong enough ties to assume or maintain this role.

The domain general integrity is related to overall satisfaction with life and family relationships. Caring for a relative with dementia at home is a full-time task and usually a long-term task (half of the participants had been caring for their relative more than five years), thereby affecting 
caregivers' personal plans for older age. Goals in older age are related to the process of life review, which involves contacts with the members of a multi-generational family and significant others, visiting significant places, and having time to reflect on the meaning of one's own life (Marx, Solomon, $\&$ Miller, 2004). Caring for a relative with dementia at least limits these opportunities. Therefore, caring for a relative with dementia transforms family relationships, which become centered on the care receiver's needs. Caregivers experience a lack of reciprocity with those who are helping them, as they are often receiving more help from relatives than in the past and are less likely to be asked to provide support to other family members. Yet, the caregiving role is a huge contribution to the family, both in symbolic terms (the value of caring for those in need) and in instrumental terms (performing a highly demanding task). In addition, caregivers also feel that this involvement makes it more difficult to resolve family conflicts. Conflicts from the past are harder to resolve as the caregiver has fewer opportunities to develop ways to deal with them; present conflicts are also harder to resolve, as caregiving can exacerbate latent conflicts because they create a very tense, long-term situation. Caregivers probably need to receive more concrete feedback and recognition regarding their contribution to the family as caregivers (Figueiredo, 2009). In this context, the role of "keeper of the meaning" (Vaillant, 2002) assumes relevance, because providing care places an elderly caregiver in the role of maintaining the family's values of union and support, which are crucial for future generations' well-being. These experiences tend to be reported by all caregivers, but some are on a pathway towards family integrity, whereas others are on trajectories that seem to lead to family disconnection and alienation. The current findings, together with those from other studies (King \& Wynne, 2004; Marques \& Sousa, 2012; Sousa et al., 2009), suggest that a key factor that affects this trajectory is how people subjectively perceive and experience events. Some processes have been identified in the literature as suitable for describing why older people tend to interpret these events differently (Sousa et al., 2009): forgiving (self and others) versus blaming others; accepting (self and others) versus controlling others; valuing (self and others) versus trivializing others. Elderly caregivers of relatives with dementia who are on route to family integrity tend to: (a) embrace this new demand, forgiving other family members (understanding their circumstances), by reducing negative responses (such as resentment) and increasing positive responses (noticing the good things that are happening); (b) accept themselves (maintaining a positive attitude, even if they are experiencing fewer family contacts) and others (understanding that they have their own life challenges); (c) assign meaning, such that they continue to feel that they are living a meaningful life, because they have new projects, focused on caring, and they also acknowledge others' contributions, respecting their availability.

In contrast, older caregivers on a trajectory towards family disconnection: (a) blame others, increasing the negative responses towards them (provoking guilt, making accusations) while feeling powerless, as being powerless, paradoxically, seems to be their source of power; (b) attempt to control others, trying to compel more visits and support, but without asking, and waiting for others to accept the blame for conflicts, because their own contributions to problems (which are inevitably present) are not recognized; (c) trivialize others, given that their attempts to contribute (for example, with instrumental support) are not recognized. For caregivers on a trajectory towards family alienation, it seems that: (a) they do not forgive (self and others) but they also do not blame others, as they just feel sad and helpless (for instance, concerning life projects); (b) they make some attempt to control others, by blaming them for not helping more, while trying to accept changes in their own life, but feeling compelled to complain about others; (c) they do not seem to trivialize (devalue) others or themselves completely, merely revealing a sense of estrangement or vagueness, almost a "non-existence".

The family integrity framework helps academics and practitioners to view caregiving and old age from a developmental perspective, which can be integrated with the traditional perspective that focuses on health problems and the impacts on caregivers' health and emotions (Sousa et al., 2009). Our results suggest two main challenges regarding intervention: (a) intervention programs should be offered before old age, because some developmental processes evolve from previous stages; (2) intervention programs for older people need to take in consideration events that have occurred during previous developmental stages. In both cases, family integrity needs to be cultivated during the life course, involving individuals, families, and practitioners.

\section{References}

Barbosa, A., Figueiredo, D., Sousa, L., \& Demain, S. (2011). Coping with the caregiving role: Differences between primary and secondary caregivers of dependent elderly people. Aging \& Mental Health, 15(4), 490-499. doi:10.1080/13607863.2010.543660

Boss, P. (2011). Loving someone who has dementia. San Francisco, CA: Jossey-Bass.

Ducharme, F. C., Lévesque, L. L., Lachance, L. M., Kergoat, M. J., Legault, A. J., Beaudet, L. M., \& Zarit, S. H. (2011). "Learning to become a family caregiver": Efficacy of an intervention program for caregivers following diagnosis of dementia in a relative. The Gerontologist, 51(4), 484494. doi:10/1093/geront/gnr014

Erikson, E. H. (1950). Childhood and society. New York, NY: W. W. Norton.

Figueiredo, D. (2009). Reinventing family caregiving: A challenge to theory and practice. In L. Sousa (Ed.), Families in later life: Emerging themes and challenges (pp. 117-134). New York, NY: Nova Science.

King, D. A., \& Wynne, L. C. (2004). The emergence of "family integrity" in later life. Family Process, 43(1), 7-21. doi:10.1111/j.1545-5300.2004.04301003.x

Lane, G. W., Podgorski, C. A., Noronha, D. O., \& King, D. (2012). "The hidden caregiver": Kinship caregivers and lessons learned from dementia family caregiving. Clinical Gerontologist, 35(2), 195-203. doi:10.1080/073 17115.2011.641708 
Marques, F. D., \& Sousa, L. (2012). Family integrity: Pathways of elderly poor persons. Paidéia (Ribeirão Preto), 22(52), 207-216. doi:10.1590/S0103$863 \times 2012000200007$

Marx, J. L., Solomon, J. C., \& Miller, L. Q. (2004). Gift wrapping ourselves: The final gift exchange. Journals of Gerontology. Series B, Psychological Sciences and Social Sciences, 59(5), S274-S280. doi:10.1093/ geronb/59.5.S274

Mason, M. (2010). Sample size and saturation in $\mathrm{PhD}$ studies using qualitative interviews. Forum: Qualitative Social Research, 11(3), art. 8. Retrieved from http:// www.qualitative-research.net/index.php/fqs/article/ view/1428/3027

Nadeau, J. W. (2001). Meaning making in family bereavement: A family systems approach. In M. S. Stroebe, R. O. Hansson, W. Stroebe, \& H. Schut (Eds.), Handbook of bereavement research: Consequences, coping and care (pp. 329-347). Washington, DC: American Psychological Association.

Pinto, F. N. F. R., \& Barham, E. J. (2014). Bem estar psicológico: Comparação entre cuidadores de idosos com e sem demência [Psychological well-being: Comparison between caregivers of older adults with and without dementia]. Psicologia, Saúde \& Doenças, 15(3), 635-655. doi:10.15309/14psd150307

Sousa, L. (2009). New themes on ageing families. In L. Sousa (Ed.), Families in later life: Emerging themes and challenges (pp. 1-25). New York, NY: Nova Science.

Sousa, L., Silva, A. R., Marques, F., \& Santos, L. (2009). Constructing family integrity in later life. In L. Sousa (Ed.), Families in later life: Emerging themes and challenges (pp. 163-186). New York, NY: Nova Science.

Sousa, L., Silva, A. R., Santos, L., \& Patrão, M. (2010). The family inheritance process: Motivations and patterns and interaction. European Journal of Ageing, 7(1), 5-15. doi:10.1007/s10433-010-0139-3

Vaillant, G. E. (2002). Aging well: Surprising guideposts to a happier life from the landmark Harvard Study of adult development. Boston, MA: Little, Brown.

Vitaliano, P. P., Zhang, J., \& Scanlan, J. M. (2003). Is caregiving hazardous to one's physical health? A metaanalysis. Psychological Bulletin, 129(6), 946-972. doi:10.1037/0033-2909.129.6.946

Walsh, F. (2012). Successful aging and family resilience. Annual Review of Gerontology and Geriatrics, 32(1), 151-172. doi:10.1891/0198-8794.32.153

Williamson, D. S. (1991). The intimacy paradox: Personal authority in the family system. New York, NY: Guilford.

World Health Organization. Global Program on AIDS. (1994). AIDS and the family: Families take care. World AIDS Day Newsletter, (2), 1.

Wynne, L. C. (1984). The epigenesis of relational systems: A model for understanding family development. Family Process, 23(3), 297-318. doi:10.1111/j.15455300.1984.00297.x
Sara Guerra is a Gerontologist at the Portuguese Red Cross in Aveiro.

Daniela Figueiredo is an Adjunct Lecturer at the Universidade de Aveiro.

Marta Patrão is a Post-Doc Researcher at the Universidade de Aveiro.

Liliana Sousa is an Auxiliary Professor at the Universidade de Aveiro.

Received: Nov. 24, 2014

1st Revision: May 25, 2015

Approved: Aug. 7, 2015

How to cite this article:

Guerra, S., Figueiredo, D., Patrão, M., \& Sousa, L. (2016). Family integrity among older caregivers of relatives with dementia. Paidéia (Ribeirão Preto), 26(63), 15-23. doi:10.1590/1982-43272663201603 